\title{
Impact of Psycho-Pedagogical Assistance in the Development of Socialization Skills for Children during Integration in Special Schools
}

\author{
Iryna Tatianchykova ${ }^{1, *}$, Olena Kovshar ${ }^{2}$, Svitlana Boiko $^{2}$ \\ ${ }^{1}$ Department of Special Pedagogy and Inclusion, Faculty Special Education, Donbas State Pedagogical University, Ukraine \\ ${ }^{2}$ Department of Preschool Education, Faculty of Pre-Schooling and Technology Education, Kryvyi Rih State Pedagogical University, \\ Ukraine
}

Received April 6, 2020; Revised June 10, 2020; Accepted July 27, 2020

Copyright $\subseteq 2020$ by authors, all rights reserved. Authors agree that this article remains permanently open access under the terms of the Creative Commons Attribution License 4.0 International License

\begin{abstract}
The problem of socializing children with intellectual disabilities is revealed in the article as well as the ways of psycho-pedagogical support for their socialization at the stage of integration under the conditions of a special comprehensive school. In terms of present-day social-economic changes in our country, the problem of preparing people with special needs (various intellectual developmental disabilities) for independent living is aggravating. It demands them not only to acquire certain knowledge and skills but also the ability to solve different life problems, to adapt to new conditions determined by life and concrete circumstances, and successfully integrate to different life activity spheres. Thus the socialization support of children should become the important area of correction work at the educational, training and rehabilitation institutions. The influence occurs only under the conditions of special organization of pedagogical process. To reach the purpose and define the peculiarities of socialization among children with intellectual disabilities, empiric methods (talking, questioning, method of export evaluation, questionnairing, interviewing) are used; Study and generalization of pedagogical experience, which reveals the state and competence of teachers concerning the provision of pupils' socialization at the stage of integration at a special general education school, are also applied. The results of introducing the special correction developmental work are represented in the article. The analysis of the results shows the considerable increase of the general socialization level as well as the level of separate indicators at the stage of integration under the conditions of a special comprehensive school. The efficiency of the correction technology of socialization for children with intellectual disabilities proposed by us is emphasized.
\end{abstract}

Keywords Socialization, Children with Intellectual
Disabilities, Stage of Integration, Correction Developmental Work

\section{Introduction}

The problem of improving the content of personality oriented education is among the priority tasks in the modern education paradigm, as well as creating modern learning technologies, introducing new approaches in teaching and upbringing methods, aimed at overcoming problems connected with children who need special support. This raises the issue of socializing children with special needs (developmental or intellectual disabilities, in particular), who cannot adapt to the independent living and work activities. Such groups of people underestimate the role of education and vocational training at school. Moreover, they do not understand the importance of defying and using their individual and psychological peculiarities and abilities in terms of new social conditions on the way of self-realization [1-4].

That is why among the primary tasks are the following: search for modern teaching technologies, new methodological approaches to the psychological and pedagogical assistance in providing socialization of children with special needs (developmental or intellectual disabilities), up-to-date understanding of educational process organizing in a special educational institution focused on social formation of the individual, as well as improving the course of teaching subjects within socializing students with intellectual disabilities. The contemporary education concept should focus on finding the ways to elicit each student's potential, to develop 
students as the integral parts of social life and to prepare for self-development and self-fulfillment $[5,6]$. Therefore, in socializing children, the essential role belongs to the conditions of special educational institutions, which are the main institutions of socialization for them. Consequently, socialization should be considered as the main task of a special school, an important area of correction and education work, the effectiveness of which involves the purposeful organization of the pedagogical process.

Despite the importance of the problem, as evidenced by pedagogical practice, its particular relevance at the current stage of social development, correction and education technology for socializing children in a special comprehensive school has not yet found proper implementation. Schools usually work on improving the adaptation effectiveness of children who are under changeable conditions of vital activities such as social, labor and psychological ones. They provide enhanced work on their labor training. However, this is not enough, since the full disclosure of socialization and the achievement of its results are possible only in the process of child's personal growth on the basis of ensuring individualization and integration. As a result, the child is able to realize and recognize his worthwhile abilities, which should be relied upon and used to the maximum extent in the further development and professional formation under the conditions of social environment, and at school in particular. That is why more detailed consideration requires determining the organizational and methodological foundations of the integration process, the completeness of its pedagogical support while child's studying at a special school. Corrective and educational technology of socializing students at the stage of integration should be an important field of work in the modern special comprehensive school, which includes consideration of the essence (features, content, methodology) of a special pedagogical impact on children with intellectual disabilities.

Thus, considering the relevance of the problem at the present and its insufficiency in theoretical and practical issues, the need to find ways to improve the effectiveness of socializing students determines the development and practical implementation assistance pedagogical system at the stage of children integration in a special comprehensive school.

\section{Purpose and Tasks}

The purpose of the article is to reveal the essence (peculiarities, structure and content) of special correction and education work aimed at ensuring the socialization of students with intellectual disabilities in terms of their integration under the conditions of a special comprehensive school, and to prove experimentally the effectiveness of its implementation.

\section{Research Methods}

The effectiveness of psychological and pedagogical influence on the students at the stage of integration has been checked according to the indicators, which are determined while its verification. They prove that the positive tendency of student socialization depends on following: various forms of adequate use of the child's psychophysical abilities, as well as the development of social and psychological qualities, which is necessary for functioning in a social group. Maintaining certain social roles is of particular importance among students, especially the need to improve the behaviour based on the interests of the team.

The following methods have been used: questioning, questionnaires, interviews, peer review, exploring the process and products of student activities, studying and generalizing pedagogical experience relevant to the support in socializing students at the integration stage in a special comprehensive school. Children are interviewed individually to explore the peculiarities of their skills for using their psychophysical abilities (inclinations, capabilities) in classroom and extracurricular work, as well as in the process of maintaining certain social roles.

The method of questioning teachers has been used to study how much they take into account the peculiarities and characteristics of children identified in the stage of individualization in the educational process of the special school in order to fulfill them. The peer review method has been used to evaluate each child, his self-realization in the class when visiting hobby groups and while performing certain assignments.

The school documentation is also examined focusing on the ways of ensuring integration support of children in a special educational institution. Close attention is paid to the peculiarities of students' education in the profession-oriented vocational training. It represents the influence of student well-defined vocational training area in terms of his individualization on his successful integration.

Through teacher interviews and the method of expert assessment, it becomes possible to investigate students' success and adequacy while performing certain social roles in class and extracurricular work, according to their capabilities and individual psychological characteristics. On the basis of the content analysis of indicators, the levels of student socializing at the stage of integration were determined: high, sufficient, medium, low, in particular.

The study of socialization of students with intellectual disabilities at the stage of integration was carried out on the basis of methods that mostly contributed to the accumulation of knowledge about a child: his/her abilities, interests, inclinations, psychophysical abilities, individual characteristics and desires to perform certain social roles in the classroom and school, which allows one to integrate into a group of peers. 
For this purpose, the following methods were used: surveys (questionnaires, interviews), expert assessment, studying of school documentation, studying and generalization of pedagogical experience on the state of students' socialization at the stage of integration in a special secondary school.

The survey method was aimed at studying the peculiarities of students' use of their psychophysical abilities (inclinations, abilities), individual characteristics (positive qualities) in classroom and extracurricular activities, as well as in the process of performing certain social roles. It was found out that the students to what extent the features revealed at the stage of individualization correlate with the types of activities, with the functions and roles they perform in the team of peers. This method involved a conversation with students and was carried out according to the questionnaires developed by us. The survey was conducted offline in an individual oral form, which was due to the age and capabilities of children. Teachers were also interviewed to clarify certain information about students (their inclinations, interests, participation in class life, school, etc.) and their parents (for more information about a child and his / her family life).

The method of questionnaires of teachers was aimed at studying their awareness of the stage of integration in the process of students' socialization, and was used to study the extent to which they take into account about identified opportunities at the stage of individualization and features of children in the educational process. Teachers had to determine how and where this was provided. Teachers were offered specially designed questionnaires offline. The questionnaires consisted of open-ended questions that they had to answer in writing without prior theoretical training.

The method of expert assessment (on a 5-point scale) was used to assess each child by teachers, and access his/her implementation in the classroom, attending workshop, fulfilling certain tasks and social roles, their compliance with the capabilities and individual psychological characteristics of children. This method was conducted orally (offline) in the presence of 3 experts (authors th article). Particular attention was paid to the argumentation of teachers' opinions on the selection of social roles for students, finding out how they really meet their capabilities and are accepted by a group of peers, meet its interests. These data were correlated with the data obtained during the conversation with students, which studied their attitude to certain tasks in the classroom, revealing the difficulties faced by students in performing social roles, which determined the child's place in peers, its acceptance by the group.

School documentation was also studied, the subject of which was the state of ensuring the integration of children in a special educational institution. The report card of each student was studied in order to establish the correspondence between grades in general and profile disciplines (we were especially interested in grades in vocational training) and his/her certain interests in a number of subjects.

Close attention was paid to the peculiarities of teaching students in the profile of vocational training. It was found out how much the profile of vocational training which is defined for the student at the stage of individualization being adequate to his/her abilities influences the success of integration.

An important place in the study was occupied by the method of testing, the results of which determined the general well-being of the student based on the use of WAM (well-being, activity, mood). It was found out how a child, his/her health, activity and mood change as a result of gradual social growth, integration in the process of socialization in school. The work was carried out in an oral individual form, taking into account the individual psychological and intellectual characteristics of the child.

\section{Outline of the Main Research Material}

The issue of socializing occupies a leading position in psychological and pedagogical studies, since its solution depends directly on the success of the inclusion of the younger generation into the independent life and work [1-3, $7,8]$. This problem is particularly critical in special pedagogy, in view of the fact that the children with special needs (developmental disabilities) experience significant difficulties in learning social experiences due to their mental abilities. That is why they need the knowledgeable assistance of specialists. On the contrary, teachers require methodological support, as they do not possess the entire understanding of socialization issues at school. The above mentioned causes bring about the necessity of a detailed study of the process of socializing, its psychological content, stages and main ways of its provision.

It should be noted that consideration of the problem involves determining the psychological and pedagogical bases of ensuring socialization among children with intellectual disabilities. Thus, the study of the psychological content of the research subject (socialization i. a.), its essence, components, stages, mechanisms, features and patterns of its formation and manifestation among children, the effective indicators of influences cover the psychological issues of this research. The pedagogical aspect of the problem is understood in terms of a single pedagogical system, the essence of which is determined by the main components of the pedagogical process (training, education) such as: the target, the content, organizational and methodological constituents [2].

The concept of socialization is interpreted broadly as the process and result of a person's social development, his entry into the social environment, adaptation to it, the development of certain roles and functions. Moskalenko notes: "Socialization is the entry of individuals into society 
through different communities, collectives, groups due to learning norms, ideals, values by means of education and training ..." [7, p. 186]. Other researchers consider the process of socialization as learning social experience, due to which an actual personality is formed $[6,9]$.

Socialization is interpreted as a continuous process in terms of which the personality acquires its development while passing through certain basic stages. The stages of socialization conditionally correspond to the age stages of human growth and development in ontogeny and its personal growth (L. Stolyarenko, 2001; I. Tatianchykova, 2017) [2, 8]. These stages include adaptation, individualization, integration and labor stages. The latter is specified to the conditions of special school as a stage of early labor training.

The stage of adaptation (from birth to adolescence) includes the following: the child learns social experience uncritically, adapts, adjusts and imitates.

The stage of individualization (adolescence) presumes that the child has a desire to distinguish himself / herself from among others, he critically considers social norms of behaviour. This stage is characterized as intermediate socialization because the outlook and the character of a teenager are still unstable.

The stage of integration (teen age and adolescence) a child has a desire to find his place in society, "to be enrolled" in society. Integration is successful if the characteristics of a person are accepted by a group or by society.

During the labor stage (the whole period of human maturity and his working activity), a person not only learns social experience, but also reproduces it due to his or her active influence on the environment through his activity.

This article considers psychological and pedagogical support of socializing students with special needs (intellectual disabilities, in particular) within the stage of integration. It should be noted that at this stage the child tends to enter and "join" the society (social group, environment), find his place in it, offering himself with his uniqueness and his abilities $[8,10]$.

This research focuses on peculiarities of socializing of students at the stage of integration. It has been conducted by means of an experiment, which has been carried out during the school year in the process of extracurricular educational work in special secondary schools of Donetsk and Dnipropetrovsk regions of Ukraine. 120 students with special needs (intellectual disabilities, in particular) have participated in the experiment. Purposeful work has been executed with the students of the experimental group (60 people). The effectiveness of socialization was determined by the above-mentioned indicators.

The results obtained reveal the insufficient level of socialization among children at the stage of integration according to the defined indicators. Summarizing the findings it can be concluded that students with special needs (intellectual disabilities, in particular) are mostly on average (41.67\%) and low (33.33\%) levels of socialization [2].

Thus, the lack of socialization of students at the stage of integration determines the need to find pedagogical tools that are aimed at improving the efficiency of this process in a special educational institution. Understanding the essence of socialization and its stages (stages of integration); the peculiarities of socialization of students according to certain indicators that are revealed at the ascertaining stage of socialization; selection of adequate psychological and pedagogical means of influence are the basis for the development of experimental methods. Based on the findings, it has been determined that pedagogical work which is focused on improving the effectiveness of socialization among students with special needs (intellectual disabilities, in particular) at the stage of integration in a special comprehensive school should be carried out consistently and gradually, on the basis of assisting this process by indicators determined according to correction and development influence.

As a result, the main content areas have been chosen, in relation to which pedagogical influence should be exercised: the use and development of the revealed characteristics and abilities of the child in extra-curricular work; the selection and assistance in maintaining various social roles by students, taking into account their peculiarities; formation of socio-psychological qualities necessary for functioning in a social group. The experimental work has been carried out on the basis of specially developed correction and educational technology, which includes the use of appropriately selected pedagogical approaches, such as: content, methods and organization forms.

The content component is presented with modules that correspond to the main areas of work at the stage of integration, in accordance with the subject of correction and developmental influence, goals and tasks. Two modules are determined: "How to make your free time interesting and useful", and "Mastering social roles". Purposeful pedagogical influence on the students involves different educational activities and is carried out in the process of extracurricular work in special classes, mainly in the front-face and group forms. Much attention is paid to individual work with students.

Offered correction technology of socializing students at the stage of integration contains the structure and content defined taking into account the above-mentioned modules. Regarding the use and development of characteristics and abilities of students during extracurricular time (module 1), it comprises the work on the propaedeutic, corrective and final stages [2].

The propaedeutic phase is focused on understanding the importance and necessity of extracurricular activities; The corrective phase is aimed at the use and development of the individual psychological peculiarities and psychophysical characteristics of students; The final stage represents 
applying the child's abilities and skills in daily life.

The correction and development program also includes the development of the social and psychological qualities necessary for the students to determine their place in the age-mate group and their acceptance by the group on the basis of their sufficient fulfillment of different social roles (module 2) [6]. The results of the summative experiment show that for a fair number of students, this process is associated with some difficulties, which are manifested primarily in their inability to adequately implement social roles within their characteristics and abilities, which cause them to be rejected by the group, making it difficult to integrate into the children collective.

The obtained results reveal that the experimental support of the educational process in a special school enables the development and realization of individual characteristics and abilities of children, to form their inclusion into the age-mate group. The students become aware of the importance of free time organizing, taking interesting and positive attitude to the results of their activities, adequately using their own psychological peculiarities in life in the process of vocational training and in the fulfillment of social roles. In this regard, the positive dynamics of the data on defined indicators also influence the overall level of socialization among students: a high level has been observed among $20.00 \%$ (in contrast with $6.67 \%$ ) as well as reducing the number of students with low levels (from $36.67 \%$ to $10,00 \%$ ) [2]. This proves the effectiveness of represented correction and education technology to ensure socialization of children with special needs (intellectual disabilities) at the stage of integration.

\section{Conclusions}

The conducted research draws the following conclusions:

According to the theoretical analysis of recent research on the raised problem, the present day scientific solution of socializing issues in special pedagogy does not satisfy the modern social needs. Despite its importance, it still remains theoretically and practically underdeveloped. The same can be observed with the integration issues within socializing processes. It is determined that the stage of integration is inherent in the emergence of the need and intention to "enter" into society relying on their personal peculiarities and abilities in order to find the proper place;

Summing up the results of empirical study of socialization among students with intellectual disabilities at the stage of integration makes it possible to determine that they are characterized by the insufficient level of socialization. At the same time, the lowest quantitative values represent the adequacy of student applying their individual psychological characteristics and abilities;

The correction and educational technology of providing socialization of students with intellectual disabilities at the stage of integration under the conditions of a special comprehensive school is developed. It comprises special structure, content, methodology and organizational forms. Correction and educational work is carried out in accordance with the defined modules and offers to organize various educational activities in terms of extracurricular work;

Experimentally, it is proved that the developed correction and educational technology is effective as it increases the efficiency of socializing students with intellectual disabilities at the stage of integration. The analysis of the results of purposeful pedagogical influence reveals a significant increase of socialization among the students of the experimental group within the general level and the level of defined indicators at the stage of integration; On the contrary, the control group students show no positive dynamics.

\section{REFERENCES}

[1] T. Zhulkovska. Socialization of People with Limited Intellectual Potentialities, Moscow Humanit.-Social Academy: Socium, Moscow, 2001.

[2] I. V. Tatianchykova. Socialization of a Child with Defects of Development: Theory, Experience, Technologies: Monograph, B.I. Matorin Publishing House, Slovians'k, 2017.

[3] R. Smith, W. Tisdall. Working with the retarded pupil in industrial arts and vocational education, Schoolshop, Vol. 24, No. 18, 58-59, 1965.

[4] O. G. Brim, S. Wheeler. Socialization after childhood. Wiley, New York, 1966.

[5] I. D. Bekh. Education of a Personality, Lybid, Kiev, 2003.

[6] P. P. Gornostay. Personality and Role: Role approach in Social Psychology of a Personality, Interpress LTD, Kiev, 2007.

[7] V. V. Moskalenko. Socialization of a Personality, Higher Sch., Kiev, 1986.

[8] L. D. Stolyarenko, Foundations of Psychology, Felix, Rostov-on-Don, 2001.

[9] P. J. Hettema. Personality and adaptation, North-Holland, Amsterdam, 1979.

[10] N. O. Myroshnychenko. Conditions of Integration of People with Functional Limitations into Society, Social Work in Ukraine: Theory and Practice Scien.-Meth. Journal, Vol. 1, No. 10, 63-68, 2005. 